\title{
Project Complexity and Risk Management (ProCRiM): Towards Modelling Project Complexity driven Risk Paths in Construction Projects
}

\author{
Abroon Qazi $^{\mathrm{a},{ }^{*},}$, John Quigley ${ }^{\mathrm{a}}$, Alex Dickson $^{\mathrm{b}}$, Konstantinos Kirytopoulos $^{\mathrm{c}}$ \\ abroon.qazi@strath.ac.uk; j.quigley@strath.ac.uk; alex.dickson@strath.ac.uk; \\ Konstantinos.Kirytopoulos@unisa.edu.au
}

${ }^{a}$ Management Science Department, Strathclyde Business School, 130 Rottenrow, Glasgow, Scotland, G4 0GE, United Kingdom

beonomics Department, Strathclyde Business School, 130 Rottenrow, Glasgow, Scotland, G4 OGE, United Kingdom

'School of Natural and Built Environments, University of South Australia, City East Campus, Adelaide, South Australia 5000, Australia

*Corresponding author. Tel: +44 7435682387; fax: +441415526686 


\section{Project Complexity and Risk Management (ProCRiM): Towards Modelling Project Complexity driven Risk Paths in Construction Projects}

Abstract-Project complexity has been extensively explored in the literature because of its contribution towards the failure of major projects in terms of cost and time overruns. Focusing on the interface of Project Complexity and Interdependency Modelling of Project Risks, we propose a new process that aids capturing interdependency between project complexity, complexity induced risks and project objectives. The proposed modelling approach is grounded in the theoretical framework of Expected Utility Theory and Bayesian Belief Networks. We consider the decision problem of identifying critical risks and selecting optimal risk mitigation strategies at the commencement stage of a project, taking into account the utility function of the decision maker with regard to the importance of project objectives and holistic interaction between project complexity and risk. The proposed process is supported by empirical research that was conducted in the construction industry in order to explore the current practices of managing project complexity and the associated risks. The experts interviewed acknowledged the contribution of the proposed process to the understanding of complex dynamics between project complexity attributes and risks. Application of the proposed process is illustrated through a simulation study.

Keywords-Project complexity; project risks; project objectives; Expected Utility Theory; Bayesian Belief Networks; empirical research

\section{Introduction}

Long-term projects involving new product development (NPD) often result in major delays and cost overruns and therefore, bearing in mind the complexity of such projects, it is extremely important to consider interdependency between risks and involve different stakeholders in identifying key risks (Ackermann et al., 2014). Complexity in projects relates to structural elements, dynamic elements and interaction of these elements across the broad categories of technical, organisational and environmental domains (Botchkarev and Finnigan, 2015; Kardes et al., 2013). There are two schools 
of thought with regard to whether risk is an element of complexity (Bosch-Rekveldt et al., 2011; Geraldi et al., 2011) or the two are distinct concepts (Saunders et al., 2015, 2016; Vidal and Marle, 2008). Different methods have been proposed for evaluating project complexity (He et al., 2015; Lu et al., 2015; Nguyen et al., 2015; Vidal et al., 2011a, b; Xia and Chan, 2012) that mainly isolate complexity from risk. Adopting such a disintegrated approach of evaluating complexity and risks in silos results in undermining the synergistic effect of interacting complexity attributes (drivers) and complexity-induced risks and raises the possibility of selecting sub-optimal risk mitigation strategies.

It is not only important to understand and evaluate project complexity but also to visualise the complex interaction between project complexity and complexity induced risks in order to prioritise critical risks and select optimal risk mitigation strategies. Moreover, these risks must also be linked to the project objectives which in turn will influence the utility of the decision maker concerning the relative importance of each project objective. Although the standard risk management process (SA, 2009) comprising different stages - namely: risk identification; risk analysis; risk evaluation; risk treatment; and risk monitoring - is generally adopted in the literature of project risk management as it presents a systematic approach of modelling risks (Schieg, 2006), the interdependency between risks and complexity is not reflected in the framework.

Project complexity attributes (drivers) pose vulnerabilities to the successful conclusion of major projects involving NPD, resulting in cost and time overruns. An important aspect of establishing a link between the knowns (represented by complexity attributes or drivers in this paper) at the commencement stage of a project and the 'known unknowns' (Ramasesh and Browning, 2014) (termed as risks in this paper) that may potentially materialise within the life cycle of the project has not been given due consideration. As we are focusing on the commencement stage of a project, the risks and strength of interaction between risks included in the model represent the belief of experts developed through learning from past experiences. However, unexpected emerging risks introduced during the life-cycle of the project and not envisioned at the commencement stage can have 
significant impact on the project objectives and therefore, besides establishing an effective risk management process, there is a need to cultivate a culture of alertness to deal with such risks categorised as 'unknown unknowns' (Ramasesh and Browning, 2014). Through this research, we are contributing to the risk management body of knowledge by addressing the following research questions (RQ):

RQ1: How is the interdependency between project complexity and complexity induced risks associated with NPD in general and construction projects in particular treated in the literature?

RQ2: How can we develop a risk management process and an effective modelling approach for capturing interdependency between complexity and risk in order to facilitate the decision making process of prioritising risks and risk mitigation strategies at the commencement stage of a project?

RQ3: How is the interdependency between project complexity and risk managed in the construction industry?

Bayesian Belief Networks (BBNs) offer an effective modelling technique for capturing interdependency between risks (Nepal and Yadav, 2015) whereas Expected Utility Theory (EUT) is widely used in decision making under uncertainty (Ruan et al., 2015). Within the theoretically grounded framework of EUT and BBNs, we propose a new process namely 'Project Complexity and Risk Management (ProCRiM)' integrating all stages of the standard risk management process (SA, 2009) and establishing causal paths across project complexity attributes, risks and their consequences affecting the project objectives. The main merit of ProCRiM is its focus on the holistic interaction between complexity and risks without taking the extreme stance of either school of thought and therefore, the results do not depend on whether complexity and risk are treated as distinct concepts or not. Rather, we contend that it is the interdependency that must be given due consideration. We represent the project complexity attributes (known at the project commencement stage) as deterministic nodes, and risks and project objectives as chance nodes. We 
also characterise the preferences of a decision maker with regard to the project objectives by means of a utility function and demonstrate the application of ProCRiM through a simulation study.

We also present our findings from 13 semi-structured interviews conducted with construction industry experts from South Australia. The empirical research helped in assessing the current techniques/tools used in the industry and evaluating the viability of ProCRiM. An overview of the research focus and the methodology adopted is presented in Fig 1 . The rest of this paper is organised as follows: An overview of the relevant literature is presented in Section 2. The proposed process and modelling approach are described in Section 3. Details of the empirical research are presented in Section 4. The application of ProCRiM is illustrated in Section 5. Findings are discussed in Section 6. Finally, our conclusions and directions for future research are presented in Section 7.

\section{Fig 1. Research focus and methodology}

\section{Literature Review}

As the focus of our research lies at the interface of project complexity and interdependency modelling of risks in NPD in general and construction projects in particular, we present a brief overview of literature in each field in the following subsections.

\subsection{Project Complexity}

Project complexity has been extensively explored within the literature on project management and a number of definitions have been proposed focusing on different dimensions including structural complexity, uncertainty, dynamics, pace and socio-political (Geraldi et al., 2011). For this study, we follow the definition proposed by Vidal and Marle (2008): 'Project complexity is the property of a project which makes it difficult to understand, foresee and keep under control its overall behaviour, even when given reasonably complete information about the project system'. In order to gain insight into the emerging themes of project complexity, we classified the studies into three streams of 
conceptual frameworks/models, complexity measurement models and empirical studies investigating the constructs of complexity within different industries.

\subsubsection{Conceptual Frameworks/Models}

A number of frameworks have been proposed to conceptualise project complexity. The notion of project complexity as 'consisting of many varied interrelated parts' and its operationalisation in terms of 'differentiation and interdependency' (Baccarini, 1996) is replicated in most of the frameworks (Geraldi et al., 2011). There is a general consensus among the researchers that complexity must encompass different facets of the project context including technical, organisational, environmental and socio-technical dimensions. However, there are two different schools of thought with regard to the concept of complexity and uncertainty (Padalkar and Gopinath, 2016). Although the frameworks considering risk as a constituent of complexity emphasise the need for integrating these together (Bosch-Rekveldt et al., 2011; Geraldi et al., 2011), this is not followed in most of the models adopted for measuring complexity (Qureshi and Kang, 2015).

Advocating the need for adopting systems thinking modelling, Williams (2005) reported that systems modelling provides an effective approach of investigating the contribution of systemic effects of project characteristics towards the time and cost overruns. In contrast to the concept of considering uncertainty as a vital part of complexity (Bosch-Rekveldt et al., 2011; Williams, 1999), Little (2005) and Vidal and Marle (2008) consider complexity and uncertainty as two separate concepts. In a similar line of thought and supporting the need for understanding dynamics between risks in complex projects, Thamhain (2013) classified the dimensions of risk management into the degree of uncertainty, project complexity and impact and introduced the risk-impact-on-performance model for describing the dynamics and cumulative nature of risks affecting performance. Danilovic and Browning (2007) compared two complementary matrix based approaches for representing, analysing and managing crucial information regarding project domains and interactions. 
Following an in-depth literature review, Vidal and Marle (2008) proposed an integrated project complexity framework comprising four categories of project size, variety, interdependence and project context, whereas Whitty and Maylor (2009) proposed viewing complexity as a matrix across structural, dynamic, independent and interacting entities. Similarly, through conducting a systematic literature review, Geraldi et al. (2011) synthesised an integrated framework for assessing the project complexity comprising five dimensions of complexity - structural, uncertainty, dynamics, pace and socio-political, while Botchkarev and Finnigan (2015) developed a 'complexity taxonomy' with respect to three levels of product, project and external environment. Using the secondary data from existing literature and primary data from interviews conducted in process engineering projects, Bosch-Rekveldt et al. (2011) presented a comprehensive framework for characterising project complexity in large engineering projects comprising technical, organisational and environmental facets of an interconnected network of organizations. In contrast to the studies focusing on country specific projects, Kardes et al. (2013) explored the structure of mega projects involving multi-country collaborations, challenges encountered during the execution and risk management techniques for dealing with the complexity.

There are a number of studies establishing links between project complexity, risks and project performance. Wallace et al. (2004) used Structural Equation Modelling (SEM) to establish relationships between project risks and project performance related to software development projects. de Camprieu et al. (2007) presented a conceptual framework capturing the impact of project characteristics on different categories of risks that in turn influence the project performance. Carvalho and Rabechini Junior (2015) introduced a conceptual model linking risk management to the project success considering the moderating effect of project complexity.

Using tertiary and bibliometric analysis, Thomé et al. (2015) synthesised the concepts of complexity, uncertainty, risk and resilience within the literatures of supply chain management and project management. They introduce a framework that links complexity and uncertainty to risk, establishing 
the indirect impact of risk management on complexity via resilience. Floricel et al. (2016) investigated the impact of complexity on project performance and confirmed their hypothesis through empirical research that there is an increase in the project performance in the presence of high levels of particular types of complexity if high levels of respective planning is present. Their results establish the link between complexity and project performance indicating the significant impact of strategies on the risks relative to different performance indicators.

\subsubsection{Theoretical Models for Evaluating Project Complexity}

Owing to the importance of evaluating project complexity, there has been significant progress in developing robust tools and techniques to measure complexity. Earlier models made use of simple matrix-based tools for scoring different characteristics of a project and calculating the average complexity value (Santana, 1990). Vidal et al. (2011a) introduced a multi-criteria approach of evaluating project complexity through the use of Analytical Hierarchy Process (AHP) considering project size, project variety, project interdependence and elements of context corresponding to organisational and technological facets. Using the similar hierarchy based modelling approach, He et al. (2015) developed a complexity measurement model based on the Shanghai Expo construction project in China using Fuzzy AHP, whereas Nguyen et al. (2015) developed a hierarchy of complexity factors and parameters in transportation projects within Vietnam. Xia and Chan (2012) identified complexity measures for building projects in China through conducting a Delphi questionnaire survey.

Qureshi and Kang (2015) developed their work on the conceptual frameworks of Bosch-Rekveldt et al. (2011) and Vidal and Marle (2008), and utilised SEM for understanding the influence of different organisational factors on project complexity rather than evaluating complexity index. They chose project size, project variety, interdependencies within the project and elements of context as the main variables within the model and validated it in different industries through survey questionnaire. 


\subsubsection{Empirical Studies}

Case studies have been conducted to understand different dimensions of project complexity and their implications on project objectives. Edkins et al. (2007) conducted multiple case studies in the construction industry and explored qualitative methods of computer-aided content analysis and causal mappings drawn from the area of managerial and organisational cognition to understand the issues related to the management of projects. Antoniadis et al. (2011) conducted five case studies in the construction industry in order to investigate the socio-organisational aspect of complexity of interactions and effects on project schedule performance. In order to link the structural complexity to emergent behaviours and project performance, Lessard et al. (2014) introduced the "House of Project Complexity" encompassing both technical and institutional elements.

Focusing on a single case study of a successful project, Koppenjan et al. (2011) investigated an upgrading project of a rail system in the Netherlands. They distinguished between two different approaches of managing projects: Predict-and-control (type I), where the risks and uncertainties are managed at the front end; and prepare-and-commit (type II), where flexibility is the norm for adapting the system with respect to changes in scope. The project did not experience major problems because uncertainty and complexity were managed through a Type I approach. Similarly, Giezen (2012) investigated how the project complexity was managed in the metro extension project of Rotterdam. The project used existing techniques and the staff were well trained in using similar technology, therefore, the technological complexity was immensely reduced. Focusing on the London Olympics 2012 Construction Program, Davies and Mackenzie (2014) classified it as a system of systems project and examined the organisational structure and process to coordinate the overall project, each individual system and interdependencies between them.

\subsection{Interdependency Modelling of Risks}

Researchers have been using different techniques for capturing interdependency between project/supply chain risks. Well-cited techniques include BBNs (Nepal and Yadav, 2015); Network 
Theory (Fang et al., 2012); Monte Carlo Simulation (Lee et al., 2012); Analytical Network Process (ANP) (Boateng et al., 2015); Causal Mapping (Ackermann et al., 2014); Systems Thinking (Williams, 2005); Interpretive Structural Modelling (Pfohl et al., 2011); and Fuzzy AHP (Nieto-Morote and RuzVila, 2011).

Fidan et al. (2011) introduced an ontology for linking risk and vulnerability to cost overrun in international construction projects. They attributed poor definition of risk and patterns of risk propagation as the major limitation of existing techniques in modelling and evaluating project risks. Following the same ontology, Yildiz et al. (2014) developed a knowledge-based risk mapping tool for cost estimation of international construction projects and Eybpoosh et al. (2011) introduced the concept of identifying risk paths in international construction projects using SEM. Using the same approach, Liu et al. (2016) explored risk paths in international construction projects performed by Chinese contractors and evaluated the impact of risks on project objectives.

Fang et al. (2012) proposed an approach of capturing the interaction between project risks using network theory. Hwang et al. (2016) used the same technique and explored the interdependencies between risks across distinct phases of the university information system development project in Taiwan. Using the similar approach of causal mapping, Ackermann et al. (2014) developed a modelling process to help project managers appreciate the impact of interactions between project risks through explicitly engaging a wide stakeholder base whereas Lin and Zhou (2011) utilised the technique of fishbone diagrams for investigating major supply chain risks faced by a focal company in relation to design changes proposed by the customers.

\subsection{Limitations of Existing Models on Project Complexity and Project Risk Management}

AHP, Fuzzy Set Theory (FST) and hybrid methods integrating the two techniques have been extensively used in modelling project complexity due to their prominence in the literature on project risk management (Taroun, 2014). The main limitation of AHP is the underlying assumption of treating criteria as independent factors. Although this limitation has been overcome with the 
introduction of ANP, there is still a major concern of eliciting a number of preferences with regard to pairwise comparison of different criteria and alternatives (Ishizaka and Labib, 2009). The main criticism of FST is its inability to provide the operational definition of the membership of a fuzzy set whereas subjective probabilities have operational definitions (Cooke, 2004).

Although interdependency modelling of project risks has been demonstrated using different techniques like ANP, SEM and network theory, these models fail to account for the propagation of risks and updating of beliefs upon receiving new information. SEM has its limitation in ensuring that necessary causal conditions have been met and therefore, the results might not guarantee causal relationships between the variables and associated strength (Bollen and Pearl, 2013).

Existing models have mainly focused on a specific stage of risk management process like risk identification and/or risk analysis whereas to the best of the authors' knowledge, an integrated project complexity and risk management process has not been presented. The mentioned techniques fail to assess risks within a probabilistic setting of interacting risks and do not focus on the risk treatment and risk monitoring stages that involve selection of optimal risk mitigation strategies and addition of new risks to the network respectively. Although some studies like Zhang and Fan (2014) and Fan et al. (2015) have focused on evaluating risk response strategies, these have the drawback that risks and strategies are treated as independent factors.

To fill this gap, we propose an integrated process namely ProCRiM grounded in the theoretical framework of EUT and BBNs. As BBNs manifest both the causal map of interdependent variables and strength of relationship between interconnected variables, these can overcome the limitations of other causal mapping tools by providing the visualisation of propagation patterns. Furthermore, as there are a number of uncertainties at the commencement stage of a project, BBNs present a unique tool to model these uncertainties and cope with incomplete information (Badurdeen et al., 2014). EUT is a well-established tool in decision making under uncertainty (Ruan et al., 2015), however, its application to the literature of project risk management and practice is quite limited (Kutsch and 
Hall, 2005). Lu and Yan (2013) investigated two main types of measurement of perceived risk in the construction projects; direct measurement and expected-utility based measurement. Their results indicate that managers use the direct measurement method. However, in real scenarios, risks are not independent but interact within a network setting.

\section{ProCRiM and Modelling Approach}

Understanding the complexity of a project before the commencement stage is of significant importance (Bosch-Rekveldt et al., 2011; Thamhain, 2013). However, in order to identify critical risks and select optimal risk mitigation strategies, the complexity attributes need to be linked to different trails of complexity induced risks. We adapt the established risk management framework (SA, 2009) as it is used widely both by researchers and practitioners (Wang, 2015). Although the description of terms and concepts used in the framework is controversial (Aven, 2011), our focus is limited to the stages involved in the process.

\subsection{Project Complexity and Risk Management (ProCRiM)}

The proposed process is shown in Fig 2 manifesting its exclusive focus on the 'systemicity' of complexity drivers and risks. Instead of treating complexity and risk in isolation, we introduce the concept of complexity and risk network. The process starts with the specification of project context in terms of defining the scope of risk management process and identifying the stakeholders involved in the process.

\section{Fig 2. Project complexity and risk management (ProCRiM) with associated inputs and outputs}

Complexity and risk network identification is a critical stage where there is a need for bringing a paradigm shift as the existing literature is rife with conventional tools and techniques of identifying risk and complexity categories without focusing on the network of interacting factors. Complexity and risk network analysis involves determining the strength of interactions between complexity drivers and risks. Instead of calculating the probability and impact values for individual risks, this stage is meant to capture the importance of each risk and complexity driver within the network 
setting. In the risk evaluation stage, the decision maker assigns a utility function to the project objectives and critical risks are identified through propagating evidence across the network. This stage must be able to provide a visual aid to the decision maker in appreciating the propagation impact of risk(s). Depending on the importance of specific project objectives, the decision maker should be able to identify critical risks.

Complexity and risk network treatment deals with the evaluation of different combinations of complexity and risk management strategies within the network setting. Sometimes, certain project complexity drivers can be adapted to manage the complexity and complexity driven risks. The proposed process flow is in contrast with the one established in the extant literature as instead of following unidirectional flow, it is an iterative process where evaluation of each combination of strategies necessitates re-assessing and re-evaluating the complexity and risk network. After determining the optimal combination of strategies, these are implemented and as complexity and risk management is a continuous process, there is a need for continuously monitoring the network and updating it on regular basis.

This process presents a unique feature of complementing two different schools of thought on the concept of complexity and risk; one considering risk as an element of complexity (Bosch-Rekveldt et al., 2011; Geraldi et al., 2011; Williams, 1999) and the other distinguishing the two (Baccarini, 1996; Little, 2005; Vidal and Marle, 2008). Majority of the existing complexity evaluation models follow the latter philosophical stance (He et al., 2015) thereby failing to account for the risks that are considered important in the former epistemological framework.

\subsection{Inputs and Outputs of the ProCRiM based Models}

The main difference of the proposed process with the established process $(S A, 2009)$ is its focus on the network of interacting project complexity drivers and project risks as shown in Fig 2 . As an input to any model governed by the proposed process, the decision maker needs to identify not only the 
complexity drivers, risks and project objective but also to establish interdependencies between these factors and the associated strength of relationships.

Considering the generic nature of project complexity elements introduced by Bosch-Rekveldt et al. (2011), we propose using these elements for establishing the complexity level of a project. However, instead of segregating these elements into distinct groups and categorising risks, we propose investigating the synergistic effect of multiple complexity elements and risks. These complexity elements are represented by rectangular nodes. We do not aim to evaluate the complexity by itself as it fails to identify the critical risks. Instead, we link the complexity elements (except the ones categorised as risks) proposed by Bosch-Rekveldt et al. (2011) to different associated risks which in turn affect the project objectives like the delivery time, cost, quality and so on. Both the risks and project objectives are represented by oval shaped nodes. Finally, the overall utility (diamond shaped node) is defined by the decision maker according to the relative importance of each project objective. All the chance nodes (risks and objectives) and complexity elements are assumed as binary variables.

As an input, the decision maker also needs to identify potential risk mitigation strategies, corresponding cost and impact across different risks. A strategy or combination of strategies can have a positive correlation with a risk or multiple risks. The output of models following ProCRiM helps in identifying critical risks and optimal risk mitigation strategies. Furthermore, emerging risks can easily be added to the established network of interacting factors.

\subsection{BBNs}

BBN is a graphical framework for modelling uncertainty. BBNs have their background in statistics and artificial intelligence and were first introduced in the 1980s for dealing with uncertainty in knowledge-based systems (Sigurdsson et al., 2001). They have been successfully used in addressing problems related to a number of diverse specialties including reliability modelling, medical diagnosis, geographical information systems, and aviation safety management among others. For 
understanding the mechanics and modelling of BBNs, interested readers may consult Jensen and Nielsen (2007), Kjaerulff and Anders (2008).

BBNs present a useful technique for capturing interaction between risk events and performance measures (Badurdeen et al., 2014). Another advantage of using BBNs for modelling risks is the ability of back propagation that helps in determining the probability of an event that may not be observed directly. They provide a clear graphical structure that most people find intuitive to understand. Besides, it becomes possible to conduct flexible inference based on partial observations, which allows for reasoning. Another important feature of using BBNs is to conduct what-if scenarios. There are certain problems associated with the use of BBNs: along with the increase in number of nodes representing supply chain risks, a considerable amount of data is required in populating the network with (conditional) probability values. Similarly, there are also computational challenges associated with the increase in the number of nodes.

\subsection{Modelling Approach}

The process for the development of our proposed framework is shown in Fig 3. The first stage of Problem Structuring involves identification of project complexity attributes (known at the project commencement stage) and objectives, risks, and development of the network structure followed by representing these as statistical variables. In the second stage of Instantiation, conditional probability values and utility values are specified for respective nodes. In the final stage of Inference, evidence in the form of project characteristics and risks is fed into the model and propagated in order to conduct sensitivity analysis. Finally, key risk factors are identified on the basis of detailed analysis and optimal mitigation strategies are planned at the commencement stage of the project.

\section{Fig 3. Flowchart for implementing ProCRiM using EUT and BBNs [adapted from Sigurdsson et al.} (2001)]

The opinion of experts (profiles shown in Fig 4) was sought on the potential efficacy of adopting ProCRiM to manage project complexity and project risks. Empirical research undertaken explored the current state of risk management practices within the construction industry, investigated the 
proposed modelling approach and attempted to identify the interdependencies between relevant project complexity elements (Bosch-Rekveldt et al., 2011) and risks (Zou et al., 2007) within construction projects.

\section{Empirical Research}

\subsection{Description of Respondents}

We conducted a total of 13 semi-structured interviews with experts in the construction industry in order to understand the current practices of managing project complexity and the associated risks. Furthermore, we sought respondents' opinion on the viability of ProCRiM and proposed modelling approach. All the respondents were selected on the basis of their experience in project risk management within the construction industry. Initial contact with the interviewees was established through an academic and industrial network of researchers and afterwards, the snowballing process (Sadler et al., 2010) was utilised to select suitable respondents. The qualifications and work experience of respondents are shown in Fig 4. The research was approved by the University of South Australia's Human Research Ethics Committee and all the interviews were conducted during June and August of 2015. In order to obviate the chance of misrepresentation and loss of data, all the interviews were audio-taped with the permission of respondents. After the completion of interviews, data was internally validated and content analysis was performed for data reduction and concept identification. Subsequently, the transcripts and deduced themes were shared with the interviewees for validation.

Fig 4. Profile of Respondents

\subsection{Findings}

In general, all the respondents agreed that risks are treated as independent factors within the construction industry and risk registers are used for identifying important risks where probability and impact values are associated with individual risks. Systemic interaction of risks is never considered either at the commencement stage of a project or within the life-cycle of a project. 
According to Respondent 10: 'No, we do not see the link of interdependency between risks in the risk management process. ... When you come to the industry, it is still challenging to implement the basic steps even in case of risk registers. The value of conducting comprehensive risk management process is not tangible and it is really difficult to gain the support from senior management'.

As the risk identification is based on the unrealistic assumption of risks being independent, there is no possibility of assessing the systemicity of risks and therefore, risk mitigation strategies are not evaluated within an interdependent setting of risks and strategies. According to Respondent 9: 'No, the current risk management techniques don't capture the interdependency between risks. In most cases, risk management is very casually done and solutions are proposed and implemented on ad hoc basis'. It was confirmed by a number of respondents that project managers rely on their intuition and past experience in managing risks. Furthermore, the level and sophistication of risk management process varies with project complexity itself. According to Respondent 5: 'Project managers take decisions on the basis of their gut feeling and experience. It is all firefighting. However, there is a marked difference between the techniques adopted in developed countries with those implemented in developing countries. But still, even in the case of projects undertaken in developed countries, interdependency modelling is not considered at all'.

Most of the respondents confirmed that project complexity is evaluated at the commencement stage of projects. However, it was revealed that project complexity is merely confined to technical aspects whereas organisational and environmental constructs of complexity are ignored. According to Respondent 4: 'The business as usual in project management narrows down the description, implication and effect of complexity into mere structural complication. The other aspects of complexity such as pace of construction, uniqueness of design/construction technique or material, uncertainty of decision making, socio-political scenario of host country/location of project, etc. are very conveniently overlooked'. 
ProCRiM and the proposed modelling approach were considered as an important tool for understanding the dynamic behaviour of risks. However, the main limitation of the proposed approach is the requirement of huge data that might not be readily available and is difficult to elicit. Regarding the efficacy of our proposed approach, Respondent 2 responded: 'If this model is able to identify critical risks specific to the industry, it will give great insight to the project manager in terms of identifying the source of critical risks and considering control actions. We do focus on past projects in terms of identifying key risks but those risks are considered in isolation'. The major reasons for lack of interest in using interdependency modelling are limited knowledge/expertise of managers in using sophisticated tools, limited support from senior management and the difficulty in populating these models in case of limited data. According to Respondent 7: '... It's partly because of higher data demand for such techniques and lack of awareness/training on the part of practitioners. These gaps can be bridged but lack of serious efforts in this direction stands out to be a major issue'.

We had also included project complexity elements except risks (Bosch-Rekveldt et al., 2011) and construction project risks (Zou et al., 2007) within the research tool that were presented to the respondents in the form of a matrix. Based on their responses, key complexity elements and project risks (selected by at least 7 respondents), and interdependencies (represented by shaded cells) were identified as shown in Table 1. Although the responses varied in relation to past experiences and general understanding of respondents, we could find some common themes emerging from the matrices. The main purpose of this exercise was not to identify a comprehensive list of key complexity elements and risks but to explore if the experts considered such interdependency to be important. It was revealed that there were certain complexity elements influencing a number of risks and similarly, key risks could be identified that were being influenced by a number of complexity elements. As our respondents were located in South Australia, they did not consider market condition and country related complexity elements to be relevant. Similarly, project size and cost were only considered important by two respondents as projects having higher cost and bigger size might not necessarily be classified as complex projects. 
Table 1. Selected project complexity elements and risks with associated interdependency (shaded cells identify interdependency between the row and column)

\section{Application of ProCRiM and Modelling Approach}

\subsection{Application Setting}

In this section, we demonstrate the application of ProCRiM and the proposed modelling approach through an illustrative simulation study as shown in Fig 5. The model representing critical risks specific to a construction project is adapted from an existing model proposed by Eybpoosh et al. (2011) who used SEM for evaluating cost overruns. However, their model considered a single node for the project complexity and linked it to a single risk category and captured a single project objective (cost). One concern associated with this model is its generalisation to different types of construction projects. Even if it is assumed that the model will be able to prioritise risks systematically, it is not foreseen to deal with the risk treatment and risk monitoring. The model used here (as shown in Fig 5) includes a limited number of project complexity attributes and risks identified by the empirical research conducted (refer to Table 1) to help readers focus on the mechanics of approach. The main purpose of presenting this simulation study is not to generalise a model representing a comprehensive list of variables and their interdependencies applicable to any construction project as, even within the same industry, each project and relevant circumstances would drive the structure of the network and the strength of interconnected variables in a different manner. Rather, we aim to demonstrate how practitioners can implement ProCRiM within the context of their projects and adopt the proposed modelling approach to prioritise risks and risk mitigation strategies.

\section{Fig 5. Simulation model developed in GeNle (2015)}

For this application, we consider eight project complexity elements as shown in Fig 5 and four project objectives, namely: timeliness; cost; quality; and market share. These objectives have been presented as negative counterparts in order to align these to the notion of risks. All risk factors and complexity elements have binary states of 'True (T)' or 'False (F)' and 'Yes' or 'No' respectively. For 
illustrative purposes, it is assumed that all objectives are equally important in the decision-maker's utility function and all complexity elements except 'Lack of experience with the involved team', 'Political instability' and 'Susceptibility to natural disasters' are each having the 'Yes' state. Expected utility is a probability-weighted average of the utility in the different states the network may be in. By engaging in risk mitigation, the probability of these states occurring changes, as does the value of the objectives. More generally, a utility function could capture different weights being assigned to different objectives, objectives may be evaluated in a non-linear way, and complementarities between objectives could be captured. Assumed conditional probability values represent the belief of experts and their past experience will help them to determine these values. The values reflect the efficacy of current risk mitigation strategies in dealing with the occurrence of different combinations of risks. If the already implemented strategies are very effective, the strength of interdependency between risks will be weak whereas ineffective strategies will yield higher values of these conditional probabilities.

\subsection{Application Results and Analysis}

Once the model was updated, the marginal probability values were evaluated as shown in Table 2. R3, R4, R6, R11 and R12 appear to have high likelihood of occurrence; however, the probability values alone do not help in identifying the critical risks. It is important to consider the strength of causal relationships and the relative importance of each risk factor in terms of improving the expected utility value. Keeping the overall utility node as the target node, we instantiated each risk factor to the two extreme states and registered the corresponding expected utility values. In order to identify key risk factors for further improvement, we calculated the percentage improvement in expected utility given complete mitigation of each risk factor in turn. Furthermore, we also calculated the percentage variation in the expected utility across two extreme states of each risk factor that represents its relative significance for monitoring.

Table 2. Prioritisation of risks and selection of potential risk mitigation strategies 
The two risk measures for each risk are shown in Table 2. R6 appears to be the most important risk having major influence on the utility function once it is mitigated. Though its probability is comparable to R3, R11 and R14, it is substantially important because of the strong dependency with the utility node. R1 is the most critical risk in terms of its major impact on the utility function if it is realised. Therefore, the second risk measure helps in identifying critical risks for monitoring whereas the first risk measure prioritises risks for improving the overall expected utility value. The relative importance of project objectives will also influence the ranking of risks because of the change in relative importance of dependency relationships.

Although prioritisation of risks is an important step of the risk management process, appropriate risk mitigation strategies can only be selected after considering holistic interaction of risks and strategies. We assume that the decision maker is considering implementation of cost-effective risk mitigation strategies out of the strategies identified in Table 2. Each strategy is represented by two states of 'Yes' or 'No' and its efficacy is represented by the strength of interdependency between the strategy and related risk(s). For the specific modelled project, we were able to evaluate the impact of various combinations of strategies on the overall utility as shown in Fig 6 .

\section{Fig 6. Impact of different combinations of risk mitigation strategies on the overall utility}

Our model helped in identifying optimal combinations of strategies yielding the maximum percentage improvement in the overall utility for various overall mitigation costs represented by red coloured points. All blue coloured points represent combinations of strategies that are dominated or sub-optimal. It is interesting to observe that an increase in the cost of mitigation from 800 to 1000 actually gives rise to a reduction in expected utility. This approach helps in differentiating optimal strategies (red coloured points) from dominated strategies (blue coloured points) for each given level of mitigation cost. It also helps the decision maker determine if investing in implementing strategies has a net benefit after considering the improvement in expected utility relative to the cost of mitigation. 
We also evaluated the impact of project characteristics on project objectives as shown in Fig 7. The projects having higher complexity level are more likely to result in cost overruns, however, the relationship is not linear as multiple project complexity elements and risks interact in non-linear and systemic manner. The variation of low market share with change in project characteristics is also shown in Fig 7. Use of innovative technology was modelled as an enabler of increasing the market share but at the same time, market share would be affected by the attributes of time overrun and quality issues. Therefore, it can be observed that there is a marked variation in the probability of low market share with respect to the change in project characteristics.

\section{Fig 7. Impact of project complexity on the project objectives}

Higher complexity level is not necessarily associated with higher probability value of low market share as market share is also influenced by the use of innovative technology. Researchers have also introduced the notion of evaluating not only risks but also opportunities within the risk management process (Hillson, 2002; Ward and Chapman, 2003). In this context, our proposed process takes into consideration the positive impact of high complexity (like newness of technology) on the project objectives (like market share) but at the same time, these innovative ventures necessitate implementing appropriate strategies to mitigate the resulting chains of risks.

\section{Discussion}

As the main aim of our research was to address three related questions, we discuss hereafter the implications of the research findings in order to explicitly address each question as follows:

RQ1: How is the interdependency between project complexity and complexity induced risks associated with NPD in general and construction projects in particular treated in the literature?

The existing frameworks within the literature of project complexity have focused on representing different dimensions of project complexity (Bosch-Rekveldt et al., 2011; Geraldi et al., 2011; Thomé et al., 2015). Although few studies focus on the nexus of project complexity, risk and performance 
(Carvalho and Rabechini Junior, 2015; Floricel et al., 2016; Thomé et al., 2015), no attempt has been made to integrate all stages of the risk management process. Generally, the scope of these studies is limited to the risk identification and/or risk analysis stage. Keeping in mind the comprehensive coverage of complexity attributes, we consider the framework developed by Bosch-Rekveldt et al. (2011) to be adaptable to any type of project and furthermore, their proposed complexity elements can be modelled as binary variables. However, instead of classifying the complexity elements and risks into technical, organisational and environmental categories and focusing on their independent evaluation, there is a need to capture systemic interaction across distinct categories.

It is important to measure project complexity (Lu et al., 2015) but this is not sufficient to understand the impact of complexity on different risks and project objectives. There is not general consensus on whether risk is an element of complexity (Bosch-Rekveldt et al., 2011; Geraldi et al., 2011) or the two concepts are distinct (Saunders et al., 2015, 2016; Vidal and Marle, 2008). We argue that there is a problem with existing studies adopting any extreme stance. Project complexity evaluation models treat complexity and risk as distinct concepts (He et al., 2015; Qureshi and Kang, 2015) and although interdependency between complexity elements is captured in some studies like He et al. (2015), the influence of complexity on risk is not addressed. In other studies, researchers consider risk as an element of complexity and categorise complexity drivers and risks independently (Bosch-Rekveldt et al., 2011) whereas such an approach does not account for the 'interdependency' notion of the complexity-risk nexus. Even if robust risk management techniques are adopted (Boateng et al., 2015), evaluating complexity and risk in isolation is sub-optimal in relation to modelling interdependency between complexity and risk.

On the basis of the reviewed literature, we can deduce that the interdependency between complexity and risk has not been adequately captured in existing models. There is a need for bringing a paradigm shift towards appreciating the importance of exploring interdependency within the same categories of complexity elements and risks and across distinct categories as well. The 
philosophical debate on the concept of complexity and risk still goes on and the proposed approach brings a new paradigm that is to assess complexity and risk through the lens of interdependency modelling. ProCRiM attempts to contribute towards this new approach.

RQ2: How can we develop a risk management process and an effective modelling approach for capturing interdependency between complexity and risk in order to facilitate the decision making process of prioritising risks and risk mitigation strategies at the commencement stage of a project?

As the standard risk management process $(\mathrm{SA}, 2009)$ is well-established in construction project management (Wang, 2015), the interdependency between complexity and risk - lacking in this approach - is not considered by practitioners. In order to address this issue we propose the ProCRiM. The main focus of the proposed process is on the management of complexity and risk network. The decision maker needs to identify a network of interacting project complexity drivers and risks. As an input, the importance of project objectives must also be elicited from the decision maker. The network presents a holistic picture of interacting project complexity attributes, risks and project objectives. Managers can visualise interaction between different risks, appreciate propagation patterns through risk paths and locate key risks endangering the success of a project.

The process also captures the decision maker's personal preference of each project objective in the form of a utility function. EUT has been widely used in the literature of risk management (Aven, 2015), however, very few studies have used the technique in the literature of project risk management. Therefore, there is a need to develop robust tools and models grounded in the framework of EUT to help practitioners prioritise risks and mitigation strategies. In contrast with the frequently used methods of AHP, ANP, FST and SEM to model project risks, the proposed technique of BBNs is efficient in integrating all stages of the risk management process and identifying not only critical risks but also optimal risk mitigation strategies. Modelling techniques other than BBNs are not robust enough to deal with the risk treatment and monitoring stages where optimal mitigation strategies are selected and new risks are identified respectively. 
The proposed process can bring a positive change in managing complex projects. Although our scope is limited to the commencement stage of the project, the process can be used throughout the project life-cycle. At the commencement stage, if the project manager is able to select adaptable strategies, these can be tailored in subsequent stages of the project. Such a continuous implementation of ProCRiM will help monitoring the state of risks and efficacy of risk mitigation strategies over the project life-cycle. Other methods and techniques can be explored that fit well with the framework of ProCRiM.

RQ3: How is the interdependency between project complexity and risk managed in the construction industry?

Existing empirical studies have focused on understanding the practices of managing complexity in large projects (Davies and Mackenzie, 2014; Koppenjan et al., 2011; Liu, 2015; Saunders et al., 2015), however, the current practices with regard to understanding and managing systemic and complex interaction of risks within the context of project complexity have not been investigated. Moreover, it is also important to explore whether practitioners consider the notion of interdependency between complexity and complexity driven risks in complex projects.

Our empirical finding of risks being treated as independent factors is in accordance with the main finding of Taroun (2014) who conducted an extensive review of the literature in Construction Risk Management. The ranking of risks on a probability-impact matrix is being commonly used within construction projects because of the ease in developing and analysing such models (Shi et al., 2015); the main problem associated with using sophisticated models is the limited awareness and experience in handling such models. However, we believe that even if the comprehensive quantitative modelling approach may not be exclusively adopted within the risk management process, use of causal mapping (the qualitative part of BBNs) can provide an insight into identifying key interdependencies between risks and such practice can help managers identify risk paths instead of focusing on independent categories of risks. 
The empirical research presented here is original in terms of investigating risk management practices within the context of project complexity focusing on interdependency modelling. We were also able to validate the adaptability of the framework proposed by Bosch-Rekveldt et al. (2011) to the construction industry. Based on the complexity-risk matrix filled in by the respondents, it was confirmed that practitioners consider such interdependency to be vital in complex projects. However, we did not particularly focus on identifying critical complexity elements and risks as the aim of conducting empirical research was to explore the current practices in the industry with regard to management of project complexity and associated risks. Similarly, the activity of linking project complexity elements to risks was planned to establish the viability of the overall idea. We may not be able to generalise the results to other industries that make use of sophisticated risk management techniques/tools that influence project performance (Carvalho et al., 2015).

\section{Conclusions}

Long-term projects involving NPD often result in major delays and cost overruns. Through reviewing the literature on project complexity and interdependency modelling of risks in NPD in general and construction projects in particular, we have established a major research gap of establishing an integrated complexity and risk management process exploring interdependency modelling between project complexity attributes (known at the commencement stage), complexity driven risks and project objectives. We have proposed a project complexity and risk management process and modelling approach for capturing the holistic interaction between the mentioned factors within the theoretically grounded framework of EUT and BBNs that present a very useful tool not only for capturing causal relationships between uncertain variables but also for establishing the strength of these interdependencies.

In order to investigate the current practices within the construction industry, we conducted 13 semistructured interviews with the experts in project risk management. Our findings confirmed that the risk management process implemented in the industry does not consider complex interaction 
between project complexity and risks and furthermore, project managers generally rely on their intuition and past experience in dealing with risks. Although project complexity is considered an important factor at the commencement stage, not all aspects of project complexity are included within the analysis. The experts considered the proposed process and modelling approach as an important contribution but they also identified challenges such as limited support from senior management and the requirement of populating such sophisticated models with data.

We demonstrated the application of our approach through an illustrative application that gave an insight into understanding dynamics across risks. We used key risks and complexity elements that were identified by our interviewees. Two parameters were calculated for each risk signifying its relative importance for the utility node in terms of complete mitigation and the variation in the expected utility value corresponding to the two extreme states. The latter parameter helps in identifying risks for monitoring as the occurrence of low probability-high impact risks would have a significant impact on the entire network of interconnected risks.

Overall, the contribution of this paper is three-fold: we have focused at the interface of broad fields and explored an important research theme that has received limited attention in the past; we have proposed a new process and an approach for modelling the interdependency between project complexity attributes, risks and project objectives that was further demonstrated through an illustrative application; and finally, we conducted empirical research to gain insight into the real practice of managing these complex interactions within the construction industry. In future, the proposed process will be validated in the context of different industries through case studies. Furthermore, empirical research will be conducted to investigate the best practices in managing complex interdependencies between project complexity and resulting risks. It will also be important to devise methods for reducing the effort in populating such models. Methods other than BBNs can be explored to implement the ProCRiM and investigate the trade-off between effort involved in developing the model and the precision of results. 


\section{Acknowledgements}

This research was supported by the Australian Government Department of Education and Training through the Endeavour Research Fellowship awarded to the first author. The authors wish to thank the editor and the anonymous reviewers for their constructive remarks that significantly helped the improvement of this paper.

\section{References}

Ackermann, F., Howick, S., Quigley, J., Walls, L., Houghton, T., 2014. Systemic risk elicitation: Using causal maps to engage stakeholders and build a comprehensive view of risks. European Journal of Operational Research. 238 (1), 290-299.

Antoniadis, D.N., Edum-Fotwe, F.T., Thorpe, A., 2011. Socio-organo complexity and project performance. International Journal of Project Management. 29 (7), 808-816.

Aven, T., 2011. On the new ISO guide on risk management terminology. Reliability Engineering \& System Safety. 96 (7), 719-726.

Aven, T., 2015. Risk assessment and risk management: Review of recent advances on their foundation. European Journal of Operational Research.

Baccarini, D., 1996. The concept of project complexity-a review. International Journal of Project Management. 14 (4), 201-204.

Badurdeen, F., Shuaib, M., Wijekoon, K., Brown, A., Faulkner, W., Amundson, J., Jawahir, I.S., Goldsby, T.J., lyengar, D., Boden, B., 2014. Quantitative modeling and analysis of supply chain risks using Bayesian theory. Journal of Manufacturing Technology Management. 25 (5), 631-654.

Boateng, P., Chen, Z., Ogunlana, S.O., 2015. An Analytical Network Process model for risks prioritisation in megaprojects. International Journal of Project Management. 33 (8), 1795-1811.

Bollen, K.A., Pearl, J., 2013. Eight Myths About Causality and Structural Equation Models, in: Morgan, L.S. (Ed.), Handbook of Causal Analysis for Social Research. Springer Netherlands, Dordrecht, pp. 301-328.

Bosch-Rekveldt, M., Jongkind, Y., Mooi, H., Bakker, H., Verbraeck, A., 2011. Grasping project complexity in large engineering projects: The TOE (Technical, Organizational and Environmental) framework. International Journal of Project Management. 29 (6), 728-739.

Botchkarev, A., Finnigan, P., 2015. Complexity in the Context of Information Systems Project Management. Organisational Project Management. 2 (1), 15-34.

Carvalho, M.M.d., Patah, L.A., de Souza Bido, D., 2015. Project management and its effects on project success: Cross-country and cross-industry comparisons. International Journal of Project Management. 33 (7), 1509-1522.

Carvalho, M.M.d., Rabechini Junior, R., 2015. Impact of risk management on project performance: the importance of soft skills. International Journal of Production Research. 53 (2), 321-340. 
Cooke, R., 2004. The anatomy of the squizzel: The role of operational definitions in representing uncertainty. Reliability Engineering \& System Safety. 85 (1-3), 313-319.

Danilovic, M., Browning, T.R., 2007. Managing complex product development projects with design structure matrices and domain mapping matrices. International Journal of Project Management. 25 (3), 300-314.

Davies, A., Mackenzie, I., 2014. Project complexity and systems integration: Constructing the London 2012 Olympics and Paralympics Games. International Journal of Project Management. 32 (5), 773790.

de Camprieu, R., Desbiens, J., Feixue, Y., 2007. 'Cultural' differences in project risk perception: An empirical comparison of China and Canada. International Journal of Project Management. 25 (7), 683-693.

Edkins, A.J., Kurul, E., Maytorena-Sanchez, E., Rintala, K., 2007. The application of cognitive mapping methodologies in project management research. International Journal of Project Management. 25 (8), 762-772.

Eybpoosh, M., Dikmen, I., Birgonul, M.T., 2011. Identification of Risk Paths in International Construction Projects Using Structural Equation Modeling. Journal of Construction Engineering and Management. 137 (12), 1164-1175.

Fan, Z.-P., Li, Y.-H., Zhang, Y., 2015. Generating project risk response strategies based on CBR: A case study. Expert Systems with Applications. 42 (6), 2870-2883.

Fang, C., Marle, F., Zio, E., Bocquet, J.-C., 2012. Network theory-based analysis of risk interactions in large engineering projects. Reliability Engineering \& System Safety. 106 (0), 1-10.

Fidan, G., Dikmen, I., Tanyer, A.M., Birgonul, M.T., 2011. Ontology for Relating Risk and Vulnerability to Cost Overrun in International Projects. Journal of Computing in Civil Engineering. 25 (4), 302-315.

Floricel, S., Michela, J.L., Piperca, S., 2016. Complexity, uncertainty-reduction strategies, and project performance. International Journal of Project Management.

GeNle, 2015. The Decision Systems Laboratory, GeNle and SMILE.

Geraldi, J., Maylor, H., Williams, T., 2011. Now, let's make it really complex (complicated): A systematic review of the complexities of projects. International Journal of Operations \& Production Management. 31 (9), 966-990.

Giezen, M., 2012. Keeping it simple? A case study into the advantages and disadvantages of reducing complexity in mega project planning. International Journal of Project Management. 30 (7), 781-790.

He, Q., Luo, L., Hu, Y., Chan, A.P.C., 2015. Measuring the complexity of mega construction projects in China-A fuzzy analytic network process analysis. International Journal of Project Management. 33 (3), 549-563.

Hillson, D., 2002. Extending the risk process to manage opportunities. International Journal of Project Management. 20 (3), 235-240. 
Hwang, W., Hsiao, B., Chen, H.-G., Chern, C.-C., 2016. Multiphase Assessment of Project Risk Interdependencies: Evidence from a University ISD Project in Taiwan. Project Management Journal. 47 (1), 59-75.

Ishizaka, A., Labib, A., 2009. Analytic Hierarchy Process and Expert Choice: Benefits and limitations. OR Insight. 22 (4), 201-220.

Jensen, F.V., Nielsen, T.D., 2007. Bayesian networks and decision graphs Springer-Verlag, New York.

Kardes, I., Ozturk, A., Cavusgil, S.T., Cavusgil, E., 2013. Managing global megaprojects: Complexity and risk management. International Business Review. 22 (6), 905-917.

Kjaerulff, U.B., Anders, L.M., 2008. Bayesian networks and influence diagrams : a guide to construction and analysis. Springer-Verlag, New York.

Koppenjan, J., Veeneman, W., van der Voort, H., ten Heuvelhof, E., Leijten, M., 2011. Competing management approaches in large engineering projects: The Dutch RandstadRail project. International Journal of Project Management. 29 (6), 740-750.

Kutsch, E., Hall, M., 2005. Intervening conditions on the management of project risk: Dealing with uncertainty in information technology projects. International Journal of Project Management. 23 (8), 591-599.

Lee, C.K.M., Yeung, Y.C., Hong, Z., 2012. An integrated framework for outsourcing risk management. Industrial Management \& Data Systems. 112 (4), 541-558.

Lessard, D., Sakhrani, V., Miller, R., 2014. House of Project Complexity-understanding complexity in large infrastructure projects. Engineering Project Organization Journal. 4 (4), 170-192.

Lin, Y., Zhou, L., 2011. The impacts of product design changes on supply chain risk: a case study. International Journal of Physical Distribution \& Logistics Management. 41 (2), 162-186.

Little, T., 2005. Context-adaptive agility: managing complexity and uncertainty. Software, IEEE. 22 (3), 28-35.

Liu, J., Zhao, X., Yan, P., 2016. Risk Paths in International Construction Projects: Case Study from Chinese Contractors. Journal of Construction Engineering and Management.

Liu, S., 2015. Effects of control on the performance of information systems projects: The moderating role of complexity risk. Journal of Operations Management. 36, 46-62.

Lu, S., Yan, H., 2013. A comparative study of the measurements of perceived risk among contractors in China. International Journal of Project Management. 31 (2), 307-312.

Lu, Y., Luo, L., Wang, H., Le, Y., Shi, Q., 2015. Measurement model of project complexity for largescale projects from task and organization perspective. International Journal of Project Management. $33(3), 610-622$.

Nepal, B., Yadav, O.P., 2015. Bayesian belief network-based framework for sourcing risk analysis during supplier selection. International Journal of Production Research, 1-22. 
Nguyen, A.T., Nguyen, L.D., Le-Hoai, L., Dang, C.N., 2015. Quantifying the complexity of transportation projects using the fuzzy analytic hierarchy process. International Journal of Project Management. 33 (6), 1364-1376.

Nieto-Morote, A., Ruz-Vila, F., 2011. A fuzzy approach to construction project risk assessment. International Journal of Project Management. 29 (2), 220-231.

Padalkar, M., Gopinath, S., 2016. Are complexity and uncertainty distinct concepts in project management? A taxonomical examination from literature. International Journal of Project Management. 34 (4), 688-700.

Pfohl, H.-C., Gallus, P., Thomas, D., 2011. Interpretive structural modeling of supply chain risks. International Journal of Physical Distribution \& Logistics Management. 41 (9), 839-859.

Qureshi, S.M., Kang, C., 2015. Analysing the organizational factors of project complexity using structural equation modelling. International Journal of Project Management. 33 (1), 165-176.

Ramasesh, R.V., Browning, T.R., 2014. A conceptual framework for tackling knowable unknown unknowns in project management. Journal of Operations Management. 32 (4), 190-204.

Ruan, X., Yin, Z., Frangopol, D.M., 2015. Risk Matrix Integrating Risk Attitudes Based on Utility Theory. Risk Analysis. 35 (8), 1437-1447.

SA, 2009. Risk Management: Principles and Guidelines (AS/NZS ISO 31000: 2009). Standards Australia, Sydney.

Sadler, G.R., Lee, H.-C., Lim, R.S.-H., Fullerton, J., 2010. Research Article: Recruitment of hard-toreach population subgroups via adaptations of the snowball sampling strategy. Nursing \& Health Sciences. 12 (3), 369-374.

Santana, G., 1990. Classification of construction projects by scales of complexity. International Journal of Project Management. 8 (2), 102-104.

Saunders, F.C., Gale, A.W., Sherry, A.H., 2015. Conceptualising uncertainty in safety-critical projects: A practitioner perspective. International Journal of Project Management. 33 (2), 467-478.

Saunders, F.C., Gale, A.W., Sherry, A.H., 2016. Mapping the multi-faceted: Determinants of uncertainty in safety-critical projects. International Journal of Project Management.

Schieg, M., 2006. Risk management in construction project management. Journal of Business Economics and Management. 7 (2), 77-83.

Shi, Q., Liu, Y., Zuo, J., Pan, N., Ma, G., 2015. On the management of social risks of hydraulic infrastructure projects in China: A case study. International Journal of Project Management. 33 (3), 483-496.

Sigurdsson, J.H., Walls, L.A., Quigley, J.L., 2001. Bayesian belief nets for managing expert judgement and modelling reliability. Quality and Reliability Engineering International. 17 (3), 181-190.

Taroun, A., 2014. Towards a better modelling and assessment of construction risk: Insights from a literature review. International Journal of Project Management. 32 (1), 101-115. 
Thamhain, H., 2013. Managing Risks in Complex Projects. Project Management Journal. 44 (2), 2035.

Thomé, A.M.T., Scavarda, L.F., Scavarda, A., Thomé, F.E.S.d.S., 2015. Similarities and contrasts of complexity, uncertainty, risks, and resilience in supply chains and temporary multi-organization projects. International Journal of Project Management.

Vidal, L.-A., Marle, F., Bocquet, J.-C., 2011a. Measuring project complexity using the Analytic Hierarchy Process. International Journal of Project Management. 29 (6), 718-727.

Vidal, L.-A., Marle, F., Bocquet, J.-C., 2011b. Using a Delphi process and the Analytic Hierarchy Process (AHP) to evaluate the complexity of projects. Expert Systems with Applications. 38 (5), 53885405.

Vidal, L.A., Marle, F., 2008. Understanding project complexity: implications on project management. Kybernetes. 37 (8), 1094-1110.

Wallace, L., Keil, M., Rai, A., 2004. How Software Project Risk Affects Project Performance: An Investigation of the Dimensions of Risk and an Exploratory Model. Decision Sciences. 35 (2), 289-321.

Wang, Y., 2015. Evolution of public-private partnership models in American toll road development: Learning based on public institutions' risk management. International Journal of Project Management. 33 (3), 684-696.

Ward, S., Chapman, C., 2003. Transforming project risk management into project uncertainty management. International Journal of Project Management. 21 (2), 97-105.

Whitty, S.J., Maylor, H., 2009. And then came Complex Project Management (revised). International Journal of Project Management. 27 (3), 304-310.

Williams, T., 2005. Assessing and moving on from the dominant project management discourse in the light of project overruns. Engineering Management, IEEE Transactions on. 52 (4), 497-508.

Williams, T.M., 1999. The need for new paradigms for complex projects. International Journal of Project Management. 17 (5), 269-273.

Xia, B., Chan, A.P.C., 2012. Measuring complexity for building projects: a Delphi study. Engineering, Construction and Architectural Management. 19 (1), 7-24.

Yildiz, A.E., Dikmen, I., Birgonul, M.T., Ercoskun, K., Alten, S., 2014. A knowledge-based risk mapping tool for cost estimation of international construction projects. Automation in Construction. $43(0)$, 144-155.

Zhang, Y., Fan, Z.-P., 2014. An optimization method for selecting project risk response strategies. International Journal of Project Management. 32 (3), 412-422.

Zou, P.X.W., Zhang, G., Wang, J., 2007. Understanding the key risks in construction projects in China. International Journal of Project Management. 25 (6), 601-614. 


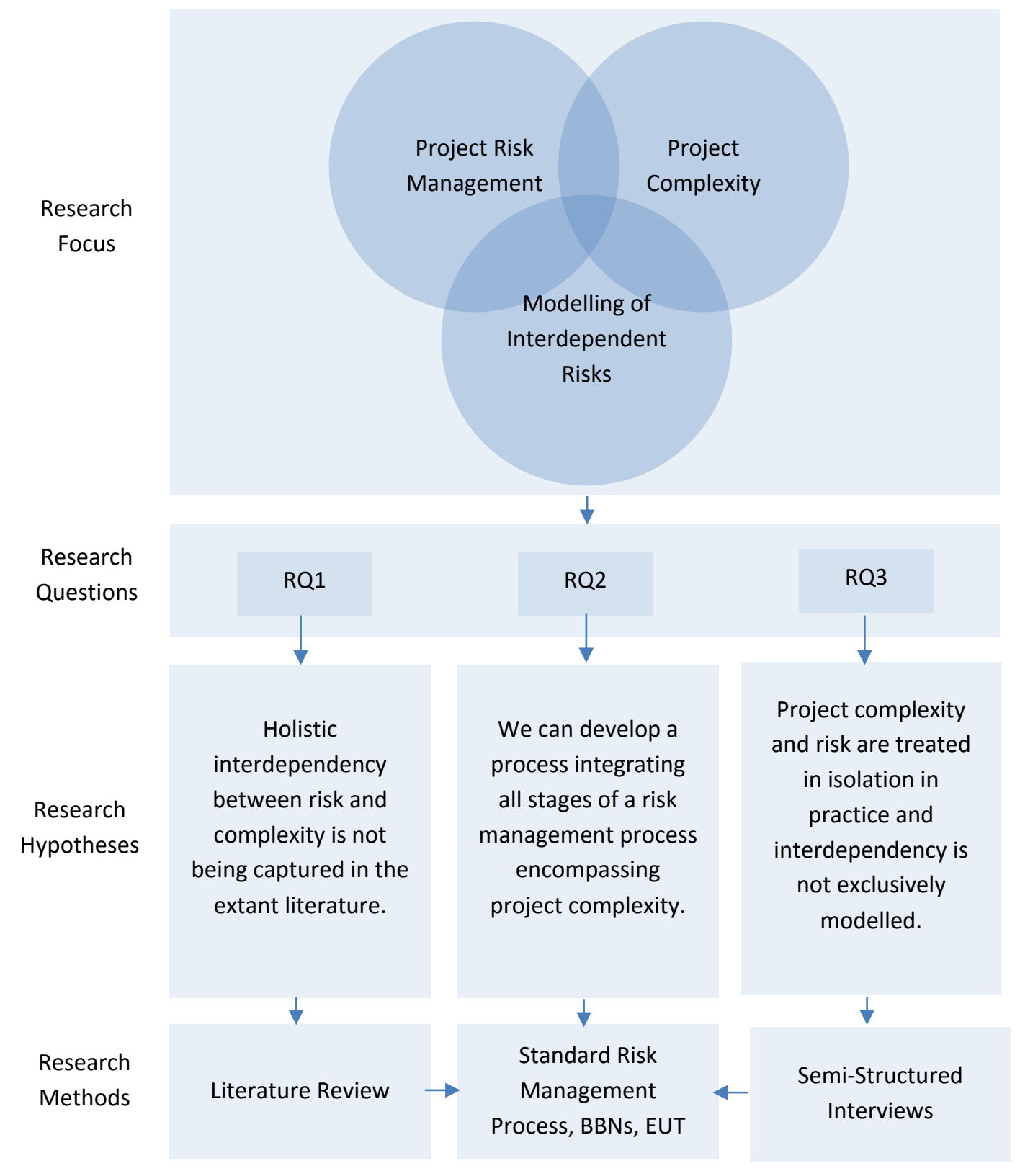

Fig 1. Research focus and methodology 


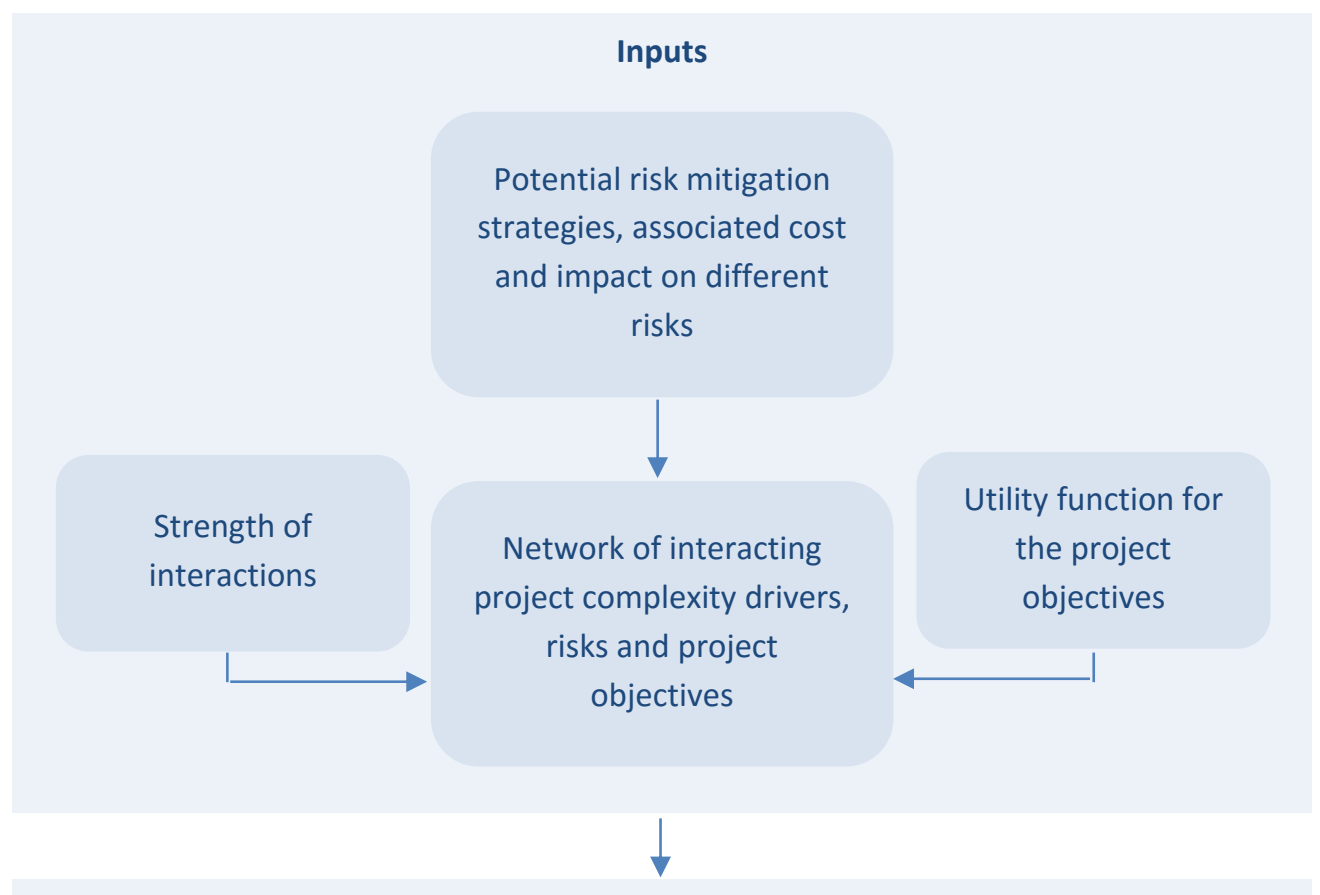

Project Complexity and Risk Management (ProCRiM)

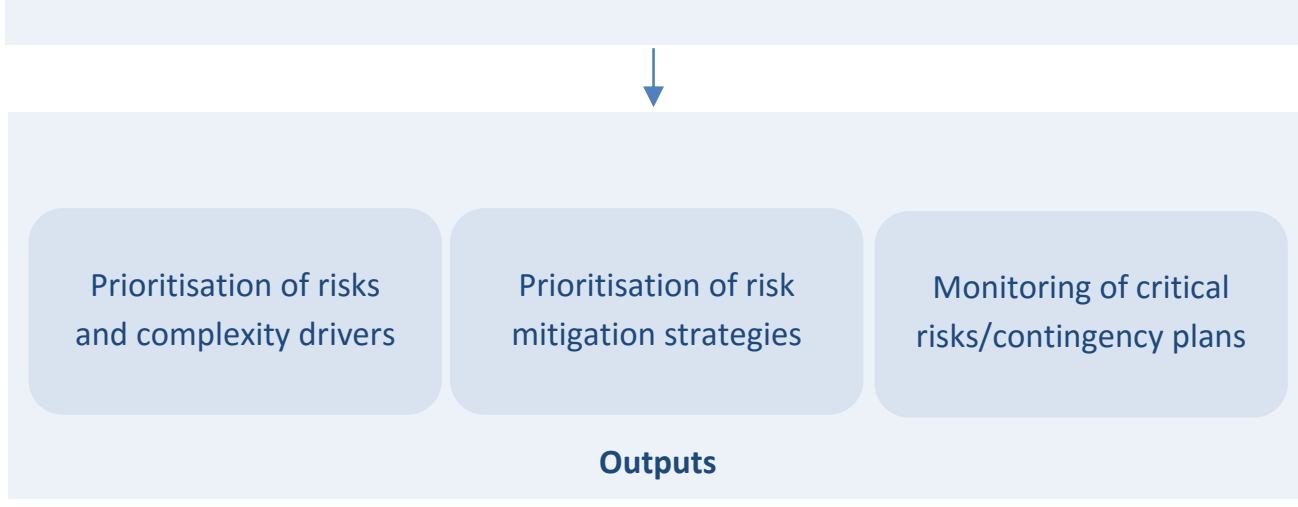

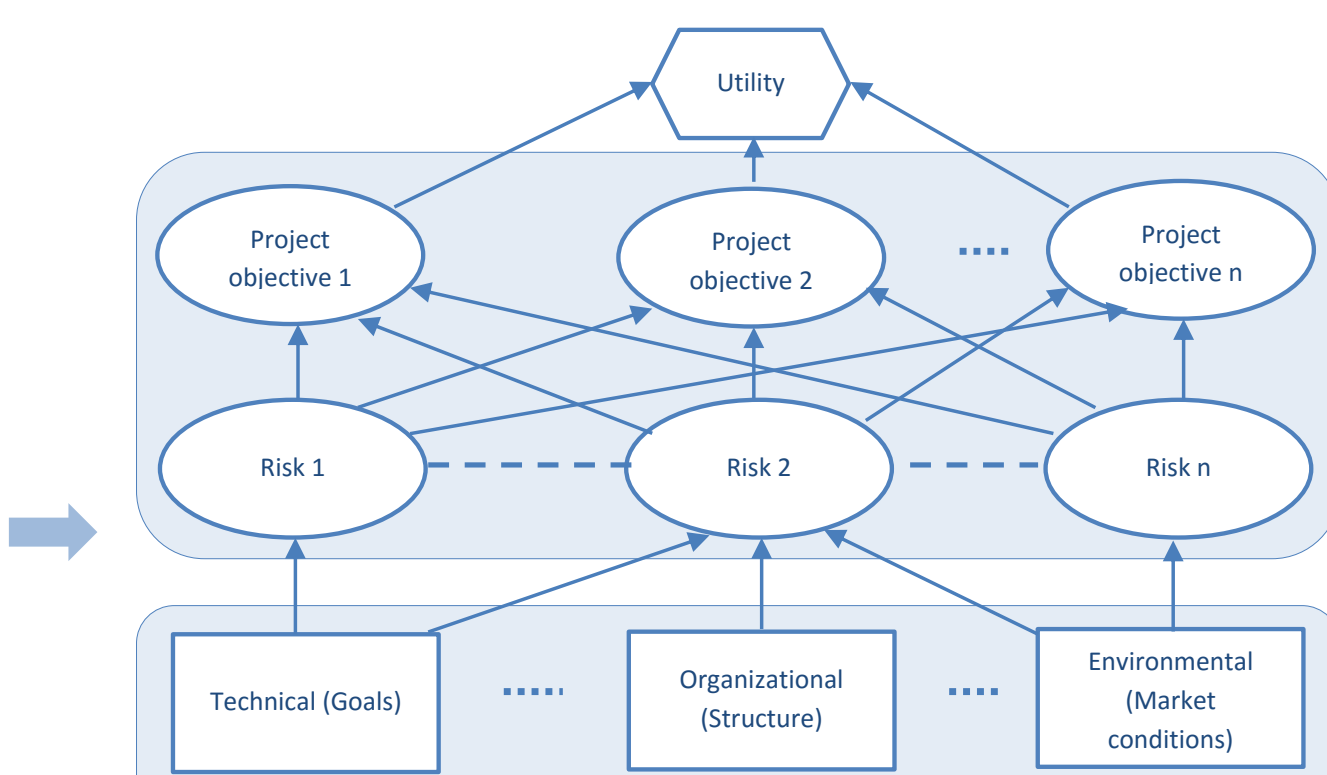

Project Complexity Elements (adapted from Bosch-Rekveldt et al., 2011)

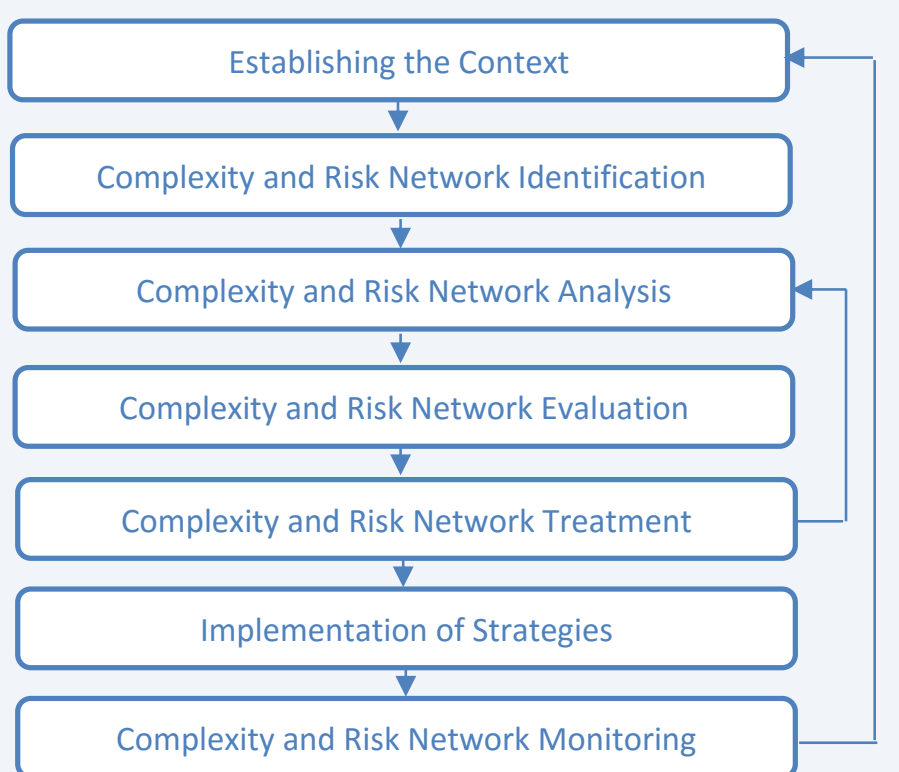

Fig 2. Project complexity and risk management (ProCRiM) with associated inputs and outputs 


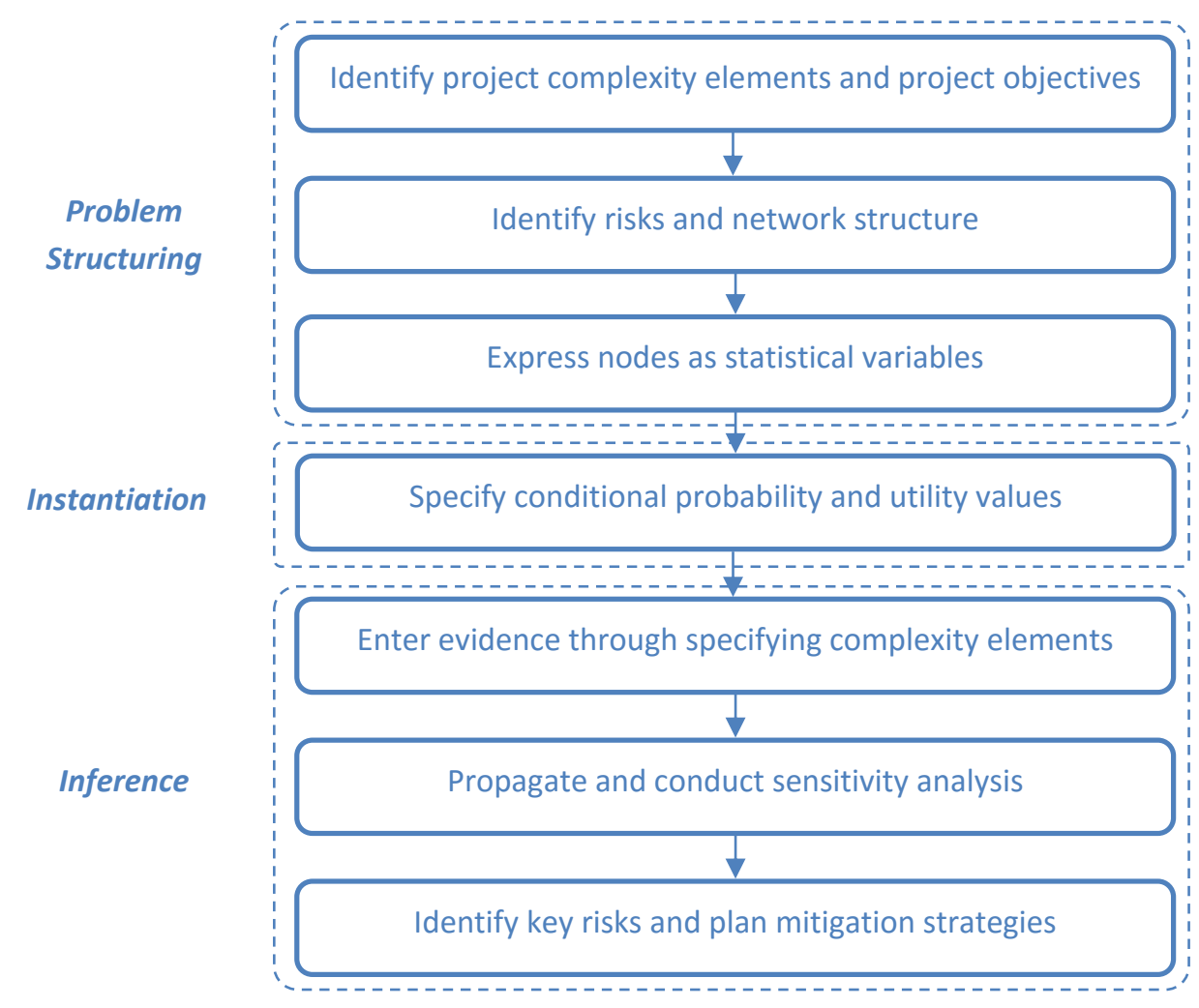

Fig 3. Flowchart for implementing ProCRiM using EUT and BBNs [adapted from Sigurdsson et al. (2001)] 


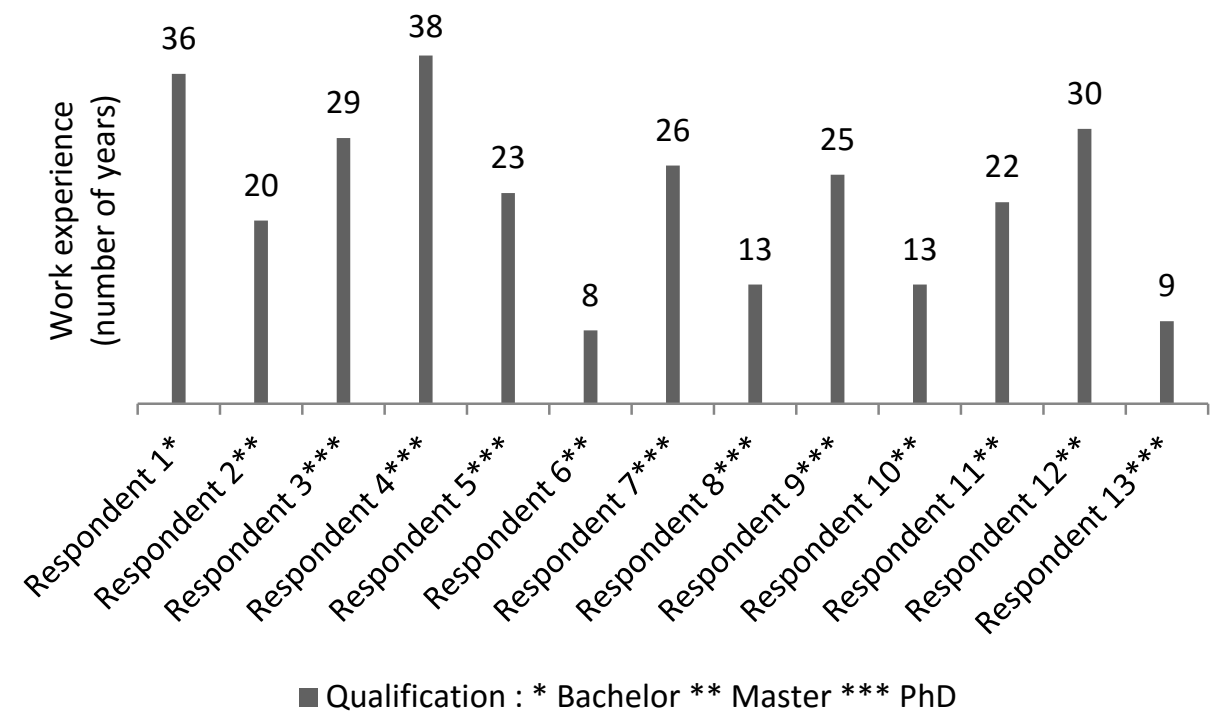

Fig 4. Profile of Respondents 


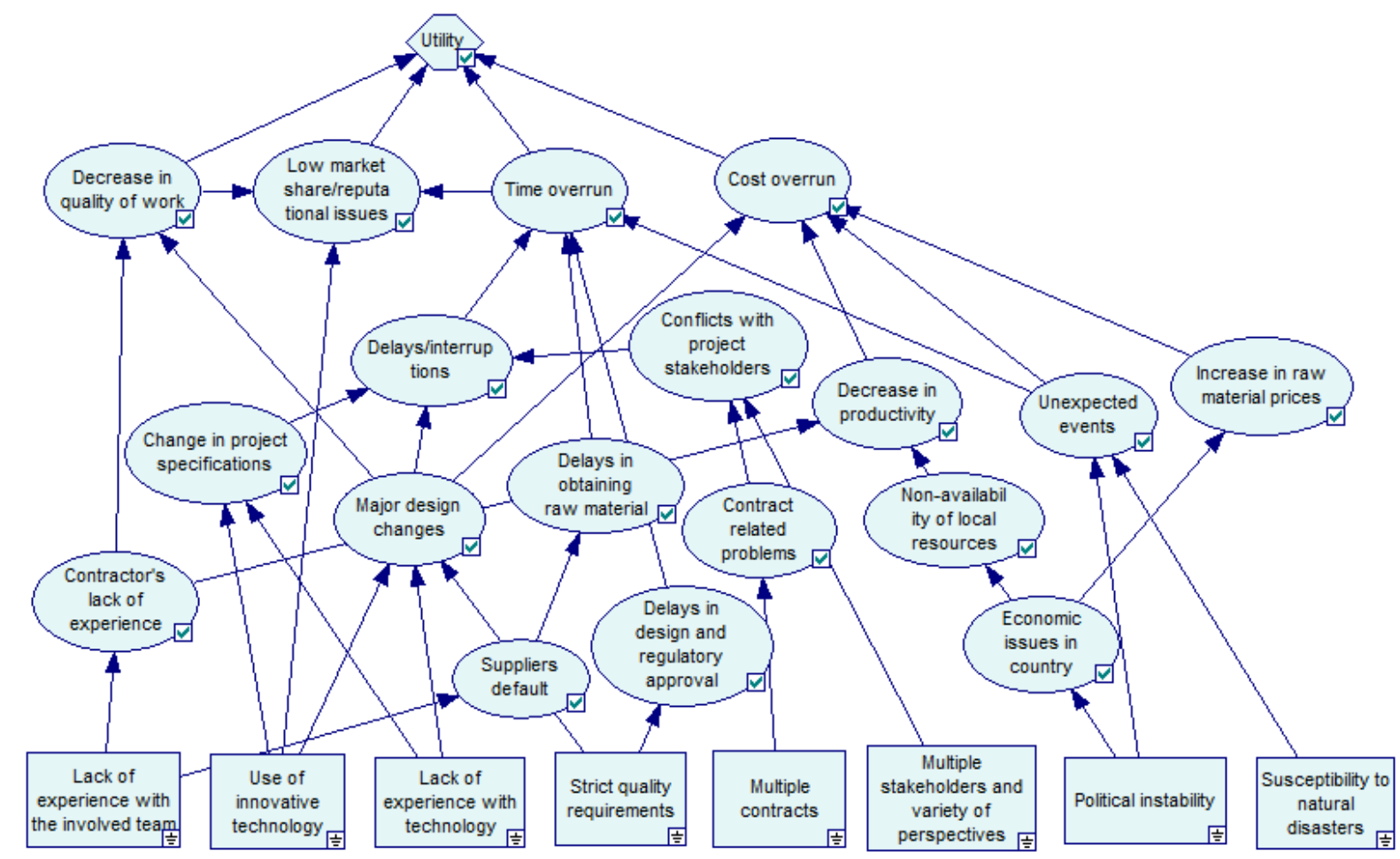

Fig 5. Simulation model developed in GeNle (2015) 


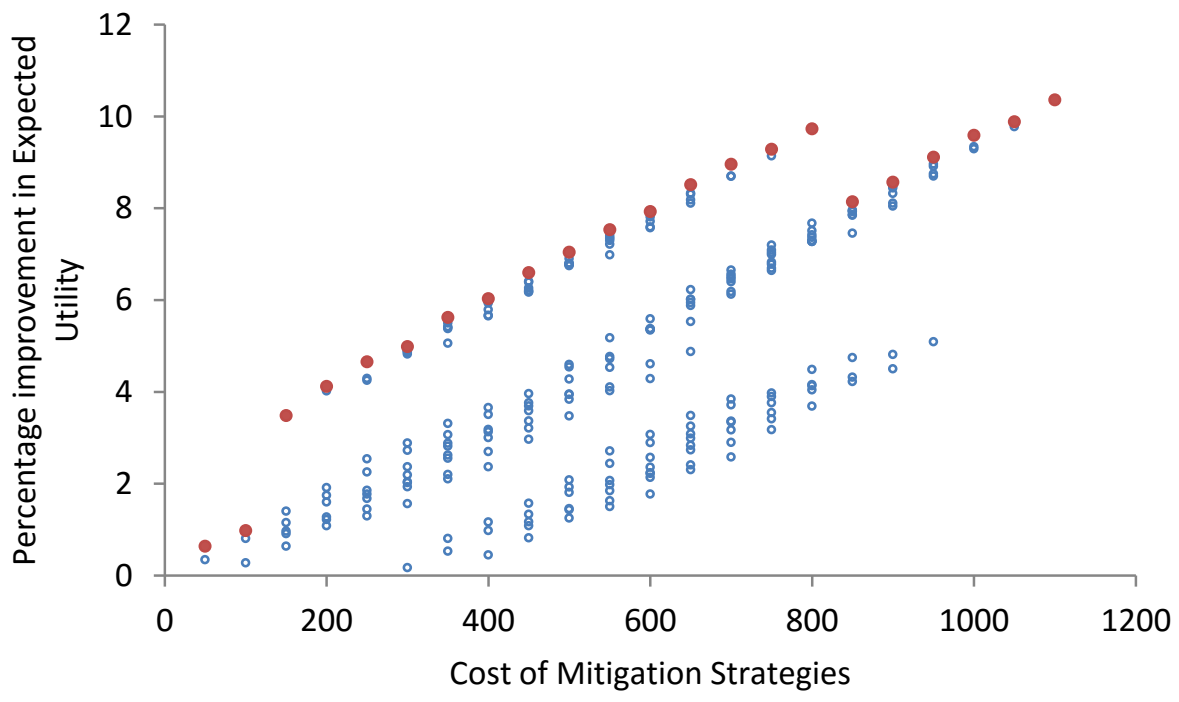

Fig 6. Impact of different combinations of risk mitigation strategies on the overall utility 


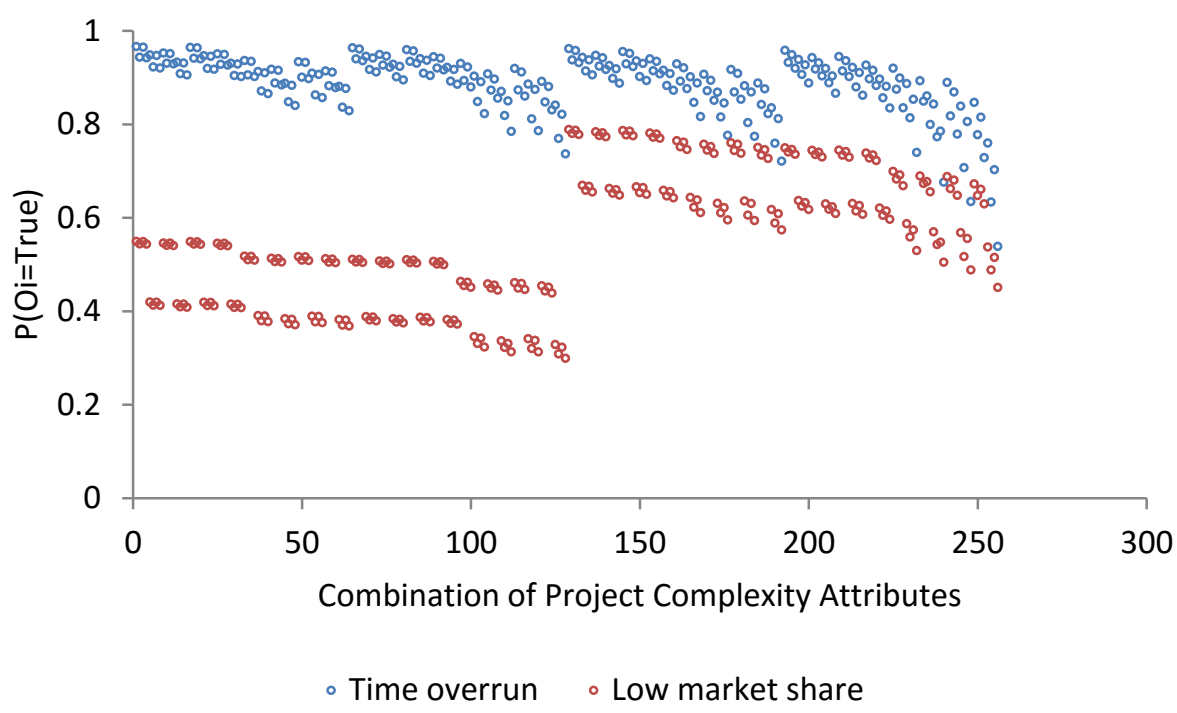

Fig 7. Impact of project complexity on the project objectives 
Table 1. Selected project complexity elements and risks with associated interdependency (shaded cells identify interdependency between the row and column)

\begin{tabular}{|c|c|c|}
\hline ID & Project Complexity Element & Category \\
\hline 1 & Lack of clarity and misalignment of goals & Technical (T) \\
\hline 2 & Ambiguity in scope & $\mathrm{T}$ \\
\hline 3 & Strict quality requirements & $\mathrm{T}$ \\
\hline 4 & Ambiguity in technical methods & $\mathrm{T}$ \\
\hline 5 & Conflicting norms and standards & $\mathrm{T}$ \\
\hline 6 & Use of innovative technology & $\mathrm{T}$ \\
\hline 7 & Lack of experience with technology & $\mathrm{T}$ \\
\hline 8 & Lack of experience with parties involved & Organisational (O) \\
\hline 9 & Multiple contracts & $\mathrm{O}$ \\
\hline 10 & Number of stakeholders and variety of perspectives & Environmental (E) \\
\hline 11 & Unstable political situation or political influence & $\mathrm{E}$ \\
\hline 12 & High Level of competition & $\mathrm{E}$ \\
\hline ID & Project Risk & \\
\hline 1 & Poor labour productivity & $\mathrm{O}$ \\
\hline 2 & Poor labour availability/shortage of skilled labour & $\mathrm{O}$ \\
\hline 3 & Defective design/quality problems & $\mathrm{T}$ \\
\hline 4 & Engineering changes/design variations & $\mathrm{T}$ \\
\hline 5 & Unwillingness to share information/lack of visibility & $E$ \\
\hline 6 & Delays in design and regulatory approvals & $\mathrm{T}$ \\
\hline 7 & Delays in obtaining required raw materials quantity & $\mathrm{O}$ \\
\hline 8 & Escalation in raw material price & $E$ \\
\hline 9 & Misalignment of interests/conflicts with stakeholders & $\mathrm{E}$ \\
\hline 10 & Increase in energy prices & $E$ \\
\hline 11 & Contract disputes & $\mathrm{E}$ \\
\hline 12 & Increase in labour cost & $\mathrm{E}$ \\
\hline 13 & Supplier/subcontractors' default & $\mathrm{O}$ \\
\hline 14 & Occurrence of dispute & $E$ \\
\hline 15 & Equipment shortage & $\mathrm{O}$ \\
\hline 16 & Non-availability of experienced design personnel & $\mathrm{O}$ \\
\hline 17 & Unavailability of sufficient managers and professionals & $\mathrm{O}$ \\
\hline 18 & Low management competency of subcontractors/suppliers & $\mathrm{O}$ \\
\hline 19 & Changes in project specifications & $\mathrm{T}$ \\
\hline 20 & Delays/interruptions & $\mathrm{T} / \mathrm{O} / \mathrm{E}$ \\
\hline
\end{tabular}

Project Complexity Element ID

1

2

3

4

5

6

7

8

9

10

11

12

$\begin{array}{llllllllllllllllllll}1 & 2 & 3 & 4 & 5 & 6 & 7 & 8 & 9 & 10 & 11 & 12 & 13 & 14 & 15 & 16 & 17 & 18 & 19 & 20\end{array}$

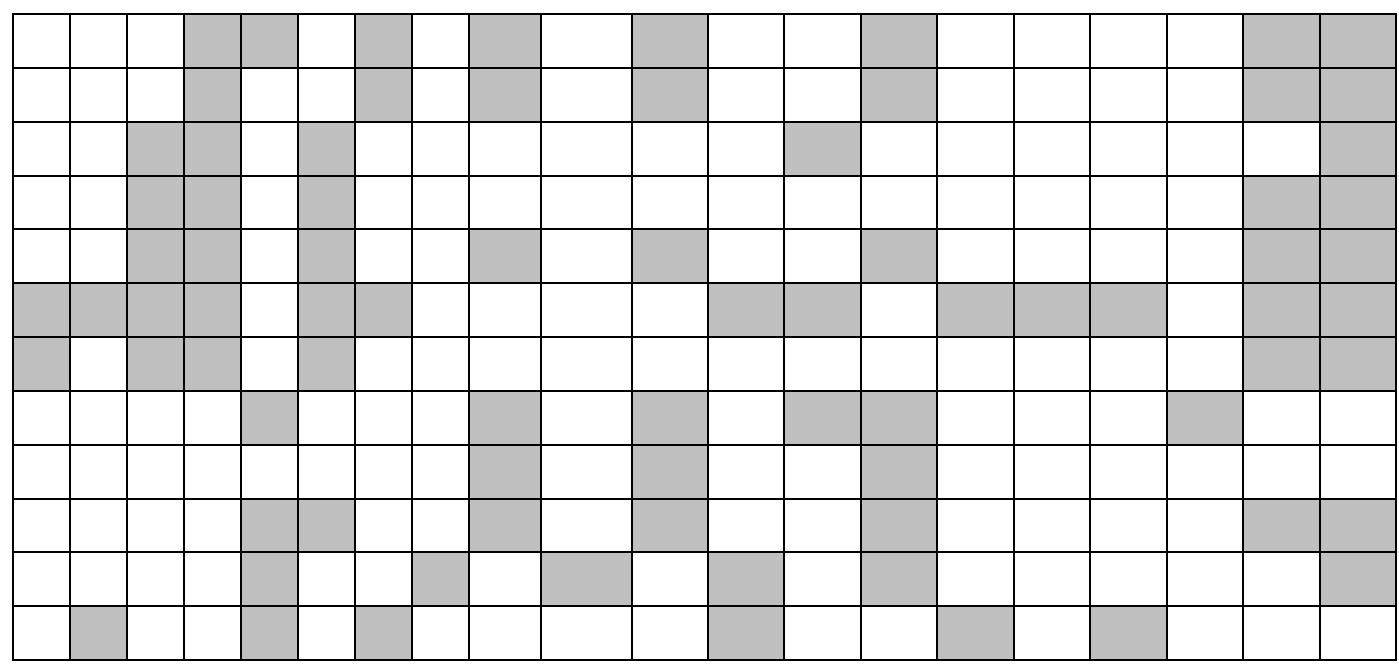


Table 2. Prioritisation of risks and selection of potential risk mitigation strategies

\begin{tabular}{|c|c|c|c|c|c|c|}
\hline \multirow[b]{2}{*}{ ID } & \multirow[b]{2}{*}{ Risk } & \multirow[b]{2}{*}{$P(R i=$ True $)$} & \multicolumn{2}{|c|}{ Risk measures } & \multirow[b]{2}{*}{$\begin{array}{l}\text { Strategy } \\
\text { ID }\end{array}$} & \multirow[b]{2}{*}{$\begin{array}{c}\text { Cost of } \\
\text { Implementing } \\
\text { Strategy }\end{array}$} \\
\hline & & & $\begin{array}{c}\% \\
\text { improvement } \\
\text { in expected } \\
\text { utility }\end{array}$ & $\begin{array}{c}\text { \% variation } \\
\text { in expected } \\
\text { utility }\end{array}$ & & \\
\hline R1 & $\begin{array}{l}\text { Contractor's lack of } \\
\text { experience }\end{array}$ & 0.05 & 3.3 & 63.7 & S1 & 200 \\
\hline $\mathrm{R} 2$ & Suppliers' default & 0.2 & 0.8 & 3.5 & S2 & 50 \\
\hline R3 & $\begin{array}{l}\text { Delays in design and } \\
\text { regulatory approvals }\end{array}$ & 0.9 & 6.3 & 7 & S3 & 150 \\
\hline R4 & Contract related problems & 0.8 & 0.4 & 0.5 & S4 & 100 \\
\hline R5 & Economic issues in country & 0.1 & 0.5 & 5.4 & & \\
\hline $\mathrm{R} 6$ & Major design changes & 0.99 & 50 & 50.5 & & \\
\hline R7 & $\begin{array}{c}\text { Delays in obtaining raw } \\
\text { material }\end{array}$ & 0.36 & 1.5 & 4.3 & S5 & 150 \\
\hline $\mathrm{R} 8$ & $\begin{array}{l}\text { Non-availability of local } \\
\text { resources }\end{array}$ & 0.25 & 1.3 & 5.3 & S6 & 100 \\
\hline R9 & Unexpected events & 0.02 & 0.3 & 13.6 & & \\
\hline R10 & Increase in raw material price & 0.27 & 1.3 & 4.7 & S7 & 50 \\
\hline R11 & $\begin{array}{l}\text { Changes in project } \\
\text { specifications }\end{array}$ & 0.95 & 0.4 & 0.4 & S8 & 300 \\
\hline R12 & $\begin{array}{l}\text { Conflicts with project } \\
\text { stakeholders }\end{array}$ & 0.85 & 0.6 & 0.7 & & \\
\hline R13 & Decrease in productivity & 0.17 & 3.6 & 20.8 & & \\
\hline R14 & Delays/interruptions & 0.98 & 10.8 & 11.1 & & \\
\hline 01 & Decrease in quality of work & 0.33 & & & & \\
\hline 02 & $\begin{array}{c}\text { Low market } \\
\text { share/reputational issues }\end{array}$ & 0.41 & & & & \\
\hline $\mathrm{O} 3$ & Time overruns & 0.91 & & & & \\
\hline 04 & Cost overruns & 0.69 & & & & \\
\hline
\end{tabular}

